\title{
Thermoluminesence and Radiocarbon Dates in the Brick Structures of GoThap Site in the Lower Mekong Delta Basin
}

\author{
Nguyen Quang Mien ${ }^{1,}$,, Nguyen Quang Bac², Bui Van Loat ${ }^{3}$, Vu Anh Hung ${ }^{3,4}$ \\ ${ }^{1}$ Institute of Archaeology, Vietnam Academy of Social Scences, Hanoi, Vietnam \\ ${ }^{2}$ Institute of Science and Technology, VINASA, Vietnam Software and IT Services Association, Hanoi, Vietnam \\ ${ }^{3}$ University of Science, Vietnam National University, Hanoi, Vietnam \\ ${ }^{4}$ Faculty of Physical and Chemical Engineering, Military Technical Academy, MOD, Hanoi, Vietnam
}

\section{Email address:}

nqmien1962@gmail.com (N. Q. Mien)

${ }^{*}$ Corresponding author

\section{To cite this article:}

Nguyen Quang Mien, Nguyen Quang Bac, Bui Van Loat, Vu Anh Hung. Thermoluminesence and Radiocarbon Dates in the Brick Structures of GoThap Site in the Lower Mekong Delta Basin. International Journal of Archaeology. Vol. 7, No. 1, 2019, pp. 17-23. doi: 10.11648/j.ija.20190701.13

Received: July 2, 2019; Accepted: July 23, 2019; Published: August 8, 2019

\begin{abstract}
The Go Thap site, formerly known as Prasat Pream Loven, is an area of six square kilometers with several small mounds on a dune running from northeast to southwest. It is situated in Thap Muoi district, Dong Thap province, Mekong Delta of Southern Vietnam. French archaeologists first explored the site during the end of the nineteenth and at the beginning of the twentieth century. This paper will establish a preliminary research of the monuments at the Go Thap site. The archaeological excavations during from 2012 to 2014 have discovered these brick monuments. We believe they are architectural foundations made of bricks sturctures. The Radiocarbon dating of the charcoal objects collected from layers of excavation indicates that these objects are from between the first late millennium $\mathrm{BC}$ and the middle of the first millennium $\mathrm{AD}$. These dates are consistent with the time of initial occupation of Go Thap in the first century BC. The thermoluminesene dating of ancient ceramic fragments found at the excavation holes are from 2nd century BC and 1st century AD. These thermoluminescence dates corresponded with the data from Angkor Borei site in Cambodia.
\end{abstract}

Keywords: Thermoluminescence Dating, Radiocarbon Dating, Lower Mekong Delta Basin

\section{Introduction}

Together with two other famous monuments - Angkor Borei and Oc Eo, Go Thap is located in the downstream of Mekong River - the longest river in south-eastern Asia and one of the longest in the world. The river starts in eastern Tibet, flows through China, Laos, Thailand, Cambodia and Vietnam. Before flowing into the Pacific, the river splits into several distributaries, to form the Lower Mekong Delta in Vietnam. Most people rely on agriculture and the natural resources of the Mekong system for food and livelihoods [5]. At the present, Go Thapspreads an area of six square kilometers with several small mounds on a dune running from northeast to southwest, and is one of the national heritage monuments of Vietnam. It is about $80 \mathrm{~km}$ from Eo Oc to the northeast and about $100 \mathrm{~km}$ from Angkor Borei to the southeast (Figure 1). These are the three most famous heritage monuments of Oc Eo culture in the lower Mekong river basin $[6,8]$.

Louis Malleret was the pioneer in researching the sites of Oc Eo (Malleret 1959, 1960, 1962), however, the war in 1945 has led to a three-decade research hiatus. In 1979, Vietnamese archaeologists resumed to work on the Oc Eo Culture sites. The 1980s and 1990s, eight brick structures were discovered in different excavations. In association with the structures, the archaeologists found several precious objects including gold leaves, a few gold rings, some gems, and pieces of glass [7, 9].

A great amount of ceramic artifacts collected from Go Thap were of a variety. Generally, they are classified into 2 types are the rough and smooth ceramics $[9,10]$. 


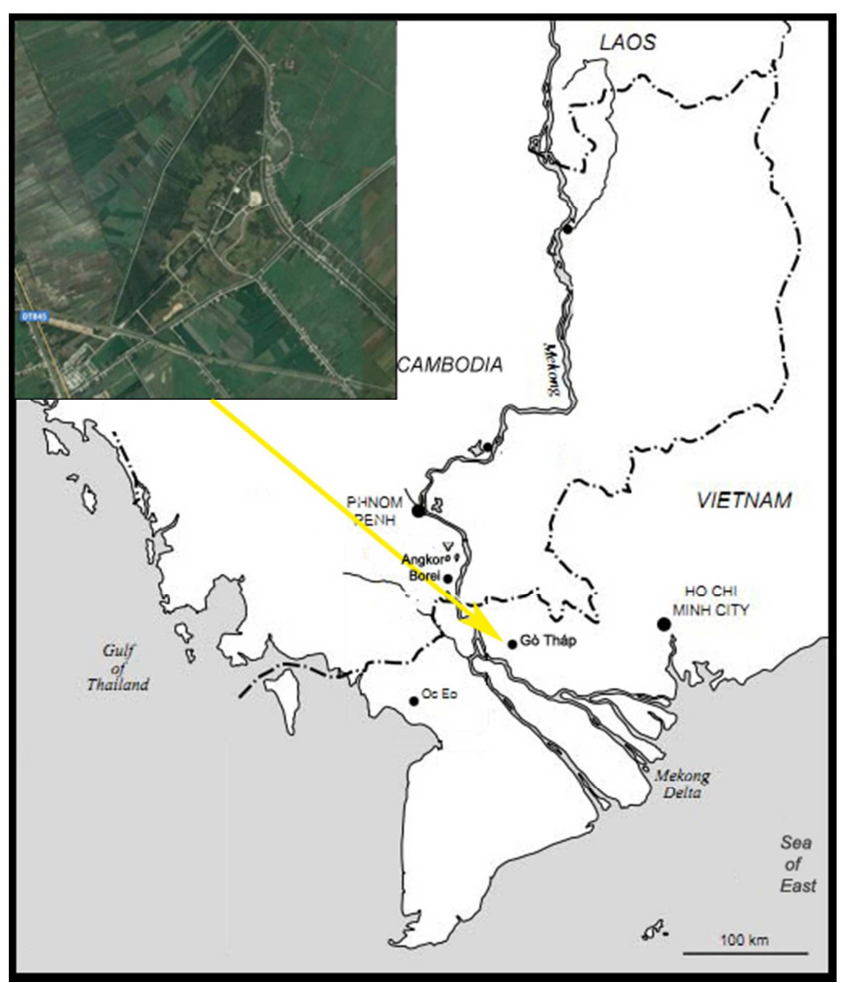

Figure 1. The location scheme of GoThap relic in the Lower Mekong river basin in Vietnam.

Rough ceramics: They are made of rough materials, as sand \& clay mix, pulverized shell \& clay mix, or crushed plant residue \& clay mix (sometimes with rice husks); the ceramic body usually is grey-brown or gray- black, the outer coat is white-grey or red. Mainly they are popular container types, like pots, vases, and bowls...

Smooth ceramics: They are made of fine materials, as: nosand fine clay mix (or very fine sand); ceramic bone usually is gray, light-gray, orange or brick-red, due to high temperature in the kiln, the outer coat is pink, light-pink or light orange. Most of them have aesthetic value or used in ceremonies with different type of vases, pots with spout and different lid types ...

Showing in Figure 2 are some typical artifacts of Oc Eo culture discovered in Go Thap.

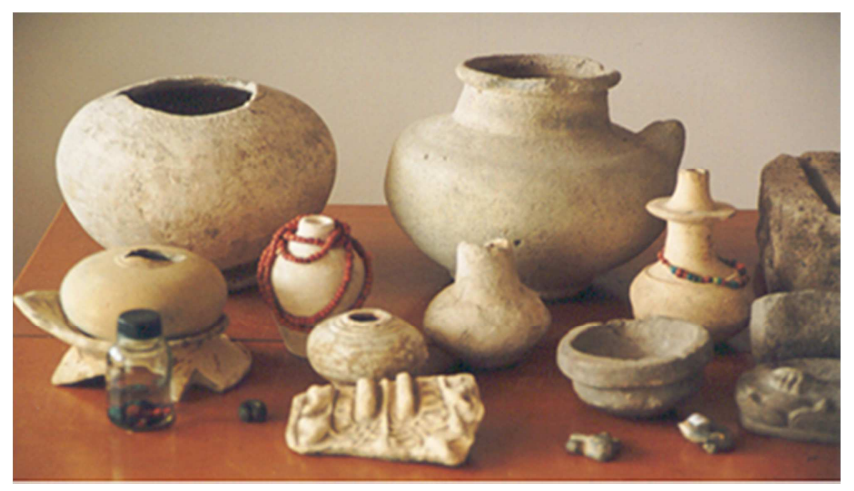

Figure 2. Some typical artitacts of Oc Eo culture discovered in Go Thap (Viet Nam).

\section{Thermoluminescence Dating Method}

The principles of thermoluminescence dating (TL) have been described very thoroughly by Aitken 1985 [1, 4]. In this paper, the quartz inclusion technique was used; the basis notion of this method is that thermoluminescene measurements are made on quartz grains, which had been etched away from the outer part. The quartz itself is relatively free of radioactivity so most of the dosages in its core are from beta, gamma and cosmic radiation $[13,14]$. By selecting grains of around $0,1 \mathrm{~mm}$ diameter before etching there is only small attenuation of the beta dosage, creating a small correction (10\%). The age of ceramic fragments is calculated using the following equation (Aitken 1985):

$$
A=\frac{P}{0.9 D_{\beta}+D_{\gamma}+D_{C}}
$$

Where: $\mathrm{P}$ is paleodose

$D_{\beta}$ is annual dose from beta radiation

$\mathrm{D}_{\gamma}$ is annual dose from gamma radiation.

$\mathrm{D}_{\mathrm{C}}$ is dose from cosmic radiation (around $0,024 \mathrm{mGy} / \mathrm{a}$ ).

After removing around $2 \mathrm{~mm}$ layer from each surface, the pottery fragments was crushed by squeezing in a vice. Grains of the desired size range are selected by sieving and then crystalline grains are separated from clay matrix by magnetic. Calcite grains are removed from the crystalline fraction with diluted hydrochloric acid and fenspat grains with concentrated hydro fluoric $[13,14]$. The stratigraphic to collect pottery segments for TL dating is illustrated in Figure 3.

The annual evironmental dose of gamma and cosmic radiation were determinated by gamma spectrometer. The annual beta dose-rate was evaluated by thermoluminescence dosimetry. The phosphor is contained in a nylon tube (internal diameter $1.2 \mathrm{~mm}$ ) which is sealed by applying pressure with hot pliers. This tube is immersed in the powdered sample for 30 days to get an accurate thermolumenescence reading. The sample needs to be pressed into the container firmly enough for it to be effective with beta particles. The mass of phosphor, CaSO4: Dy, is about 20mg $[15,16]$. All was placed in a shield box made of leads. The dose rate obtained were illustrated in Table 1.

The paleodose was evaluated by the linear extrapolating the natural thermoluminescence measurements of a quartz grains portion; and comparing it with the artificial thermoluminescence from that same portion of grains after being exposed to a known dosage of radiation from a radioisotope source ${ }^{137} \mathrm{Cs}$. However, this simple procedure usually gives only an approximate value because the sensitivity of the thermoluminescence have a tendency to be changed during the first heating (Figure 5).

In the dose additive method, several of these portions are used for natural thermoluminescence measuring; others are used for natural plus artificial thermoluminescence measuring. The thermoluminescence intensitivities are plotted as in Figure 4 and the equivalent dose $\mathrm{Q}$ is evaluated. Therefore, the value $\mathrm{Q}$ obtained is not necessarily equal to 
the paleodose. Using the intercept point I as indicated, the paleodose is taken to be $\mathrm{Q}+\mathrm{I}$. The evaluation for correction of $\mathrm{I}$ is as shown in Figure 5.

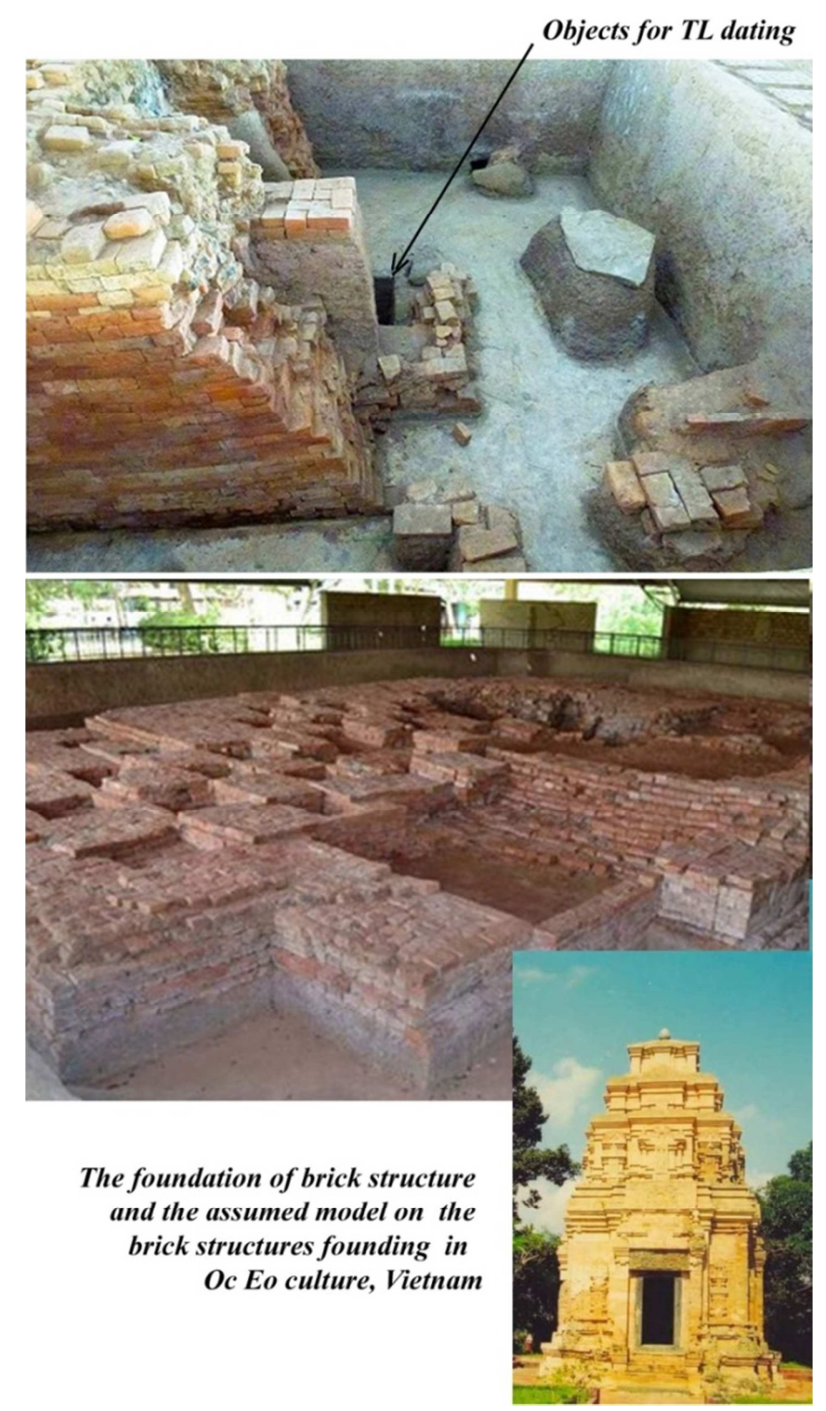

Figure 3. The stratigraphic to collect pottery segments for TL dating in Go Thap monument.

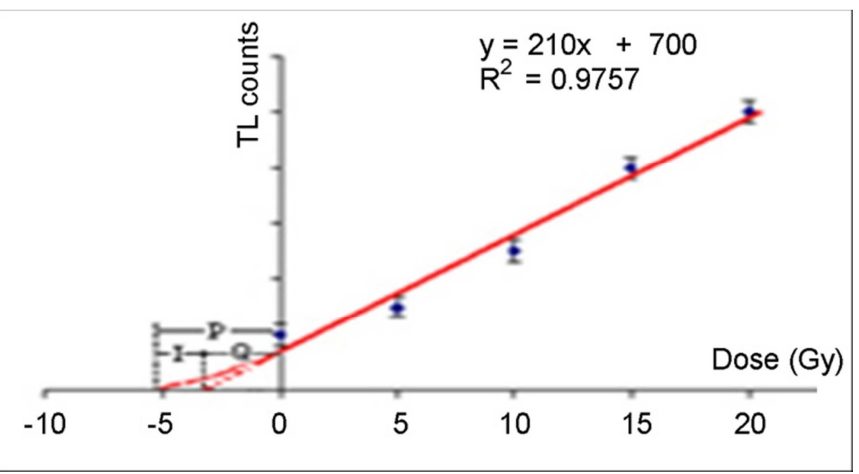

Figure 4. The additional method for evaluation of the equivalent dose $Q$ (often referred to as ' $E D$ ').

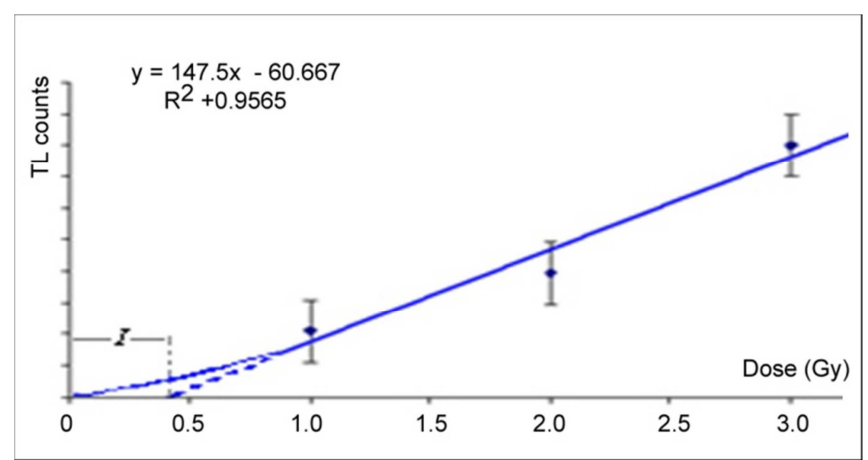

Figure 5. The second-glow growth characteristic for evaluation of the supralinearity correction value (I).

At least three levels of additive dose that are administered with gamma radiation should be used in order to check for linearity response the higher level of the natural thermoluminesence. The paleodose $\mathrm{P}$ of the previous sample is usually greater than $\mathrm{Q}$ because of the initial non-linearity response. Evaluation for the correction of $\mathrm{I}$ is as shown in Figure 5.

Then, the paleodose is given by:

$$
\mathrm{P}=\mathrm{Q}+\mathrm{I}
$$

The samples collection from Go Thap, in excavation hole 1, layer 4. This step is considered as the first part of the thermoluminescence dating program in labotory. In the first stage of experiment TL dating, in order to make it easier, we used the quartz grain technique. So, we have chosen the rough thick pottery fragments with approximate size of $2 \mathrm{~cm} \times 5 \mathrm{~cm}$ $\mathrm{x} 1 \mathrm{~cm}$ (NguyenQuangMien et al 2009). There are eight pottery fragments chosen for thermolumenesence dating, and they are illustrated in the following pictures (Figure 6).

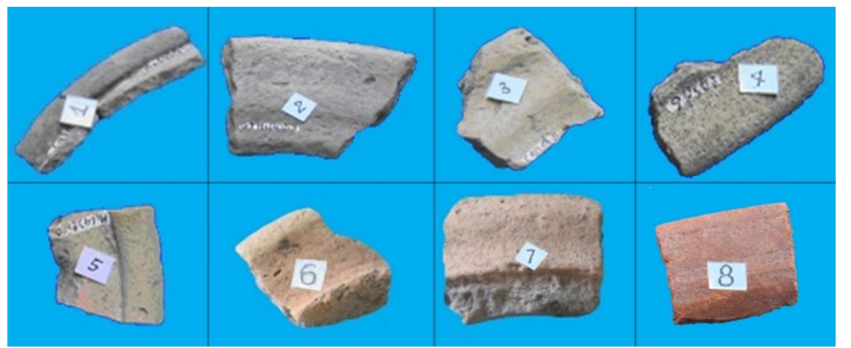

Figure 6. The pottery fragments used for thermolumenesence dating.

After removing around $2 \mathrm{~mm}$ layer from each surface, the pottery fragments was crushed by squeezing in a vice. Grains in the desired size range (90 to $120 \mu \mathrm{m}$,) are selected by sieving and then crystalline grains are separated from clay matrix by magnetic. Calcite grains are removed from the crystalline fraction with dilute hydrochloric acid and fenspat grains with concentrated hydrofluoric $[14,15]$.

The pottery fragments weighed about $30 \mathrm{~g}$ and from $0,2 \mathrm{~g}$ of etched quartz grains were obtained. Then each sample was divided into 5 portions. In dose additive method, measurements are made on a number of weighed portions of the quartz grains, usually in the region of $5 \mathrm{mg}$ each. Several of these portions are used for measurement of the natural thermoluminescence, others used for measurement of natural 
plus artificial thermoluminescence. These portions were irradiated with the different artificial doses are: 0Gy, $1 \mathrm{~Gy}$, 2Gy, 3Gy, 5Gy. Then, thermoluminescence signal from them were measured by equipment RGD-3advanced (Figure 7).

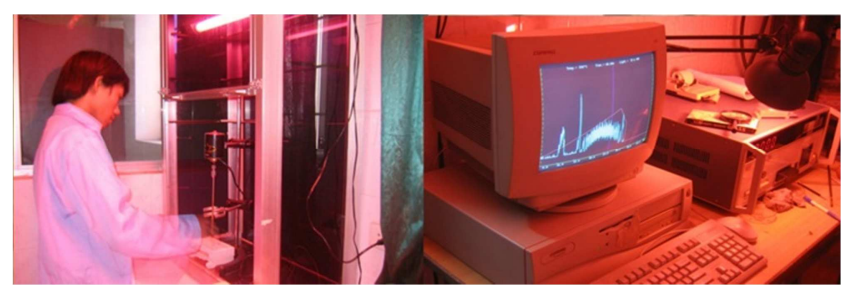

Figure 7. Treatment sample and measuremt thermoluminecence in the Laboratory.

The thermoluminescence glow-curves observed from the portions with the different aftificial irradiation doses were shown in the Figure 8. The portions were given various additive doses of gamma radiation from ${ }^{137} \mathrm{Cs}$ source (i.e., 1Gy, 2Gy, 3Gy, 5Gy). The TL0, TL1, TL2, TL3 and TL5 curves illustrate the light emission obtained from the quartz portion to which the artificial doses corresponding of: $\mathrm{N}$; $\mathrm{N}+1 \mathrm{~Gy} ; \mathrm{N}+2 \mathrm{~Gy} ; \mathrm{N}+3 \mathrm{~Gy}$ and $\mathrm{N}+5 \mathrm{~Gy}$, they were observed at heating rate of $6^{\circ} \mathrm{C} / \mathrm{sec}$ in a nitogen atmosphere.

From the thermoluminescence glow curves obtained by the linear extrapolation procedure (Figure 7), we evaluated the equivalent doses and paleodose values for the dating equation, using the integral range of $265^{\circ} \mathrm{C}$ to $400^{\circ} \mathrm{C}$ which corresponds approximately to half of the height of the TL signal form a natural sample (Figure. 8).

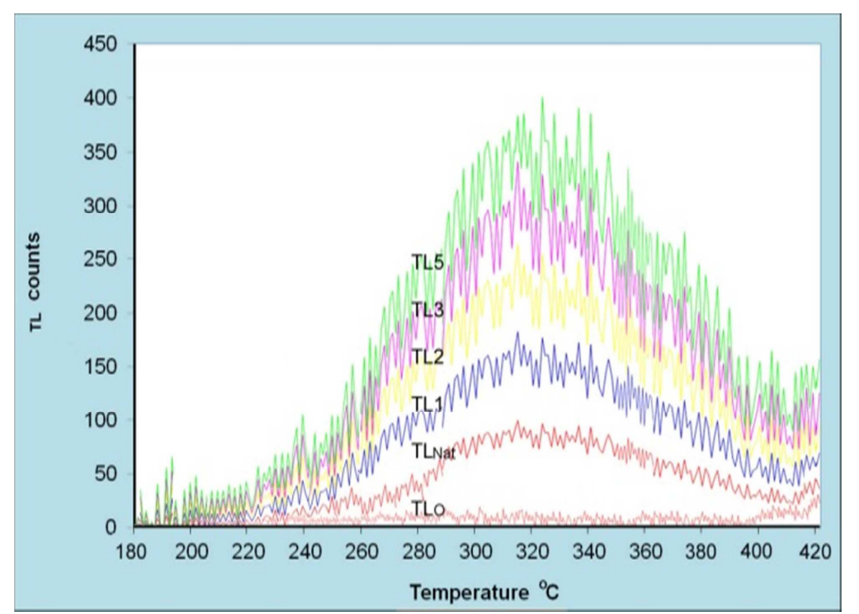

Figure 8. Glow curves of a quartz grains: TLo=Black body emission; TLNat $=$ Natural $T L ; T L 1=$ Natural $T L+1 G y ; T L 2=$ Natural $T L+2 G y ; T L 3=$ Natural $T L+3 G y ; T L 5=$ Natural $T L+5 G y$.

This range was used since it contained two TL peaks that overlap (commonly referred to as the $325^{\circ} \mathrm{C}$ and $375^{\circ} \mathrm{C}$ peaks with lifetimes of $10^{8} \mathrm{yr}[1]$. The results obtained in Table 1 already have the adjustment of water content in the excavated fragments $(20 \%$ of the dry ceramic).

Table 1. Radioactivity data measured from thermoluminescence dosimeters.

\begin{tabular}{|c|c|c|c|c|c|c|c|}
\hline \multirow[t]{2}{*}{ Items } & $\begin{array}{l}\text { Equivalent dose } \\
\text { (Gy) }\end{array}$ & Intercept (Gy) & $\begin{array}{l}\text { Paleodose } \\
\text { (Gy) }\end{array}$ & $\begin{array}{l}\text { Gamma dose } \\
\text { rate (Gy/ka) }\end{array}$ & $\begin{array}{l}\text { Beta dose rate } \\
(\mathrm{Gy} / \mathrm{ka})\end{array}$ & $\begin{array}{l}\text { Cosmic dose } \\
\text { rate }(\mathrm{Gy} / \mathrm{ka})\end{array}$ & $\begin{array}{l}\text { Total dose rate } \\
\text { (Gy/ka) }\end{array}$ \\
\hline & (Q) & (I) & (P) & $\mathbf{D}_{\gamma ; \mathbf{k}}$ & $\mathbf{D}_{\beta ; \mathbf{k}}$ & $\mathbf{D}_{\mathrm{C}}$ & $\mathbf{D}_{\mathbf{O}}$ \\
\hline 02GT.H1.L4.M1 & $1,377 \pm 0,042$ & $0,092 \pm 0,007$ & $1,468 \pm 0,049$ & $0,356 \pm 0,012$ & $0,416 \pm 0,016$ & $0,024 \pm 0,002$ & $0,754 \pm 0,029$ \\
\hline 02GT.H1.L4.M2 & $1,403 \pm 0,042$ & $0,100 \pm 0,008$ & $1,503 \pm 0,050$ & $0,357 \pm 0,012$ & $0,416 \pm 0,017$ & $0,024 \pm 0,002$ & $0,756 \pm 0,030$ \\
\hline 02GT.H1.L4.M3 & $1,457 \pm 0,048$ & $0,110 \pm 0,007$ & $1,567 \pm 0,055$ & $0,352 \pm 0,012$ & $0,411 \pm 0,016$ & $0,024 \pm 0,002$ & $0,746 \pm 0,029$ \\
\hline 02GT.H1.L4.M4 & $1,422 \pm 0,043$ & $0,083 \pm 0,007$ & $1,505 \pm 0,050$ & $0,356 \pm 0,012$ & $0,391 \pm 0,016$ & $0,024 \pm 0,002$ & $0,732 \pm 0,028$ \\
\hline 02GT.H1.L4.M5 & $1,390 \pm 0,042$ & $0,092 \pm 0,007$ & $1,482 \pm 0,048$ & $0,356 \pm 0,012$ & $0,420 \pm 0,016$ & $0,024 \pm 0,002$ & $0,758 \pm 0,029$ \\
\hline 02GT.H1.L4.M6 & $1,450 \pm 0,050$ & $0,093 \pm 0,007$ & $1,543 \pm 0,057$ & $0,356 \pm 0,012$ & $0,417 \pm 0,016$ & $0,024 \pm 0,002$ & $0,755 \pm 0,029$ \\
\hline 02GT.H1.L4.M7 & $1,445 \pm 0,042$ & $0,107 \pm 0,007$ & $1,552 \pm 0,048$ & $0,355 \pm 0,012$ & $0,417 \pm 0,016$ & $0,024 \pm 0,002$ & $0,754 \pm 0,029$ \\
\hline 02GT.H1.L4.M8 & $1,443 \pm 0,050$ & $0,093 \pm 0,007$ & $1,537 \pm 0,057$ & $0,355 \pm 0,012$ & $0,412 \pm 0,016$ & $0,024 \pm 0,002$ & $0,750 \pm 0,029$ \\
\hline
\end{tabular}

Using the derived values for the paleodose and the dose rates in Table 1, following the equation 1, the pottery fragments ages were determined. The results obtained are shown in the Table 2.

Table 2. The TL ages for pottery fragments collection from Go Thap.

\begin{tabular}{lllll}
\hline No & Items & Code Lab. & Years & Description \\
\hline 1 & 02GT.H1.L4.M1 & TL - 200623 & $1946 \pm 104$ & Rough pottery, black - gray core, no paint \\
2 & 02GT.H1.L4.M2 & TL - 200624 & $1989 \pm 107$ & Fine pottery, black - gray core, no paint \\
3 & 02GT.H1.L4.M3 & TL - 200625 & $2100 \pm 105$ & Rough pottery, black - gray core, paint pink \\
4 & 02GT.H1.L4.M4 & TL - 200626 & $2056 \pm 109$ & Rough pottery, black - gray core \\
5 & 02GT.H1.L4.M5 & TL - 200627 & $1954 \pm 101$ & Fine pottery, black - gray core, paint pink \\
6 & 02GT.H1.L4.M6 & TL - 200628 & $2043 \pm 108$ & Fine pottery, black - gray core, paint pink \\
7 & 02GT.H1.L4.M7 & TL - 200629 & $2057 \pm 108$ & Fine pottery, black - gray core, paint pink \\
8 & 02GT.H1.L4.M8 & TL - 200630 & $2050 \pm 109$ & Fine pottery, black - gray core, paint pink \\
\hline
\end{tabular}

The results in Table 2 illustrated, that ancient pottery fragments in the brick structures at Go Thap are around

$1946 \pm 104$ years BP to $2100 \pm 105$ years BP. 


\section{Radiocarbon Dating Method}

Beside, dating the ancient pottery fragments from archaeological site using thermoluminescence technique, some organic samples collected from excavation site were dated using the radiocarbon isotope technique. The radiocarbon dating samples collected from the fieldwork was shown in Figure 9.

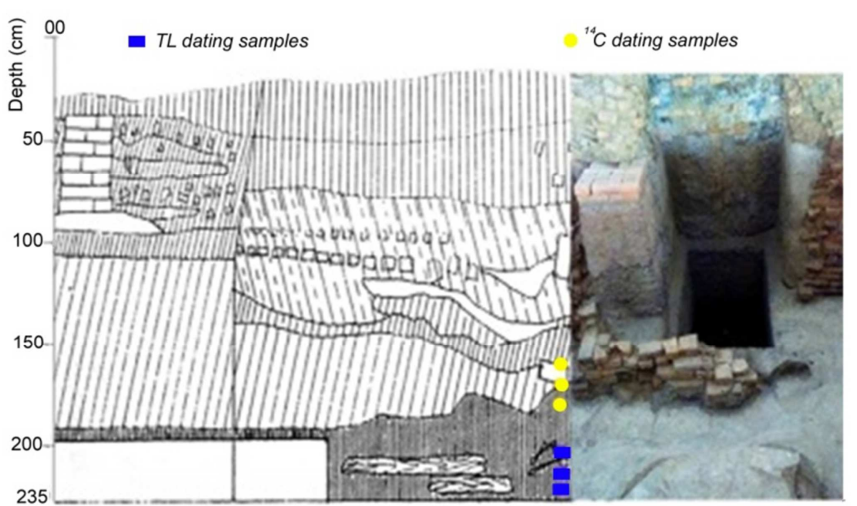

Figure 9. Cross-section of the excavation hole in the Go Thap structure monument.

In this paper, the radiocarbon dating consists of chemical treatment, benzene synthesis and counting beta radioactivity from carbon-14 by liquid scintillation analyzer (Figure 10).

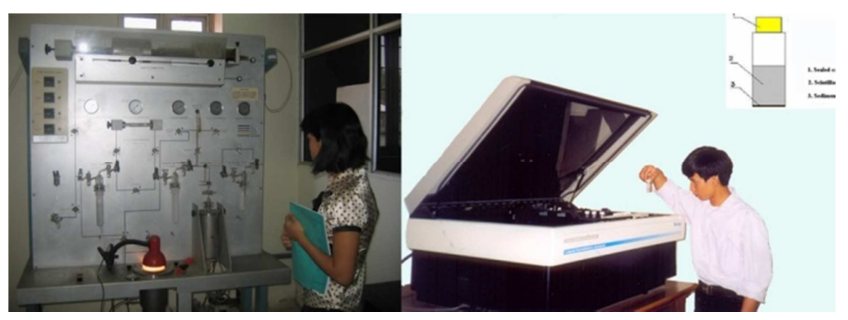

Figure 10. Practising benzene synthesis and measuremt beta radioactivity in the Laboratory.

The ${ }^{14} \mathrm{C}$ dates were shown in Table 3 .

In this Table, there are also three samples of which were dated by AMS technique from the AMS laboratory in University of Arizona (USA). The ${ }^{14} \mathrm{C}$ ages were given some comments:

a) The radiocarbon dates performed in Hanoi are consistent with that from the AMS laboratory in Universiry of Arizona.

b) There isn't any distinguish amongst the stratigraphic in the excavation hole.

c) On average, the calibrated radiocarbon dates are ranging from $1^{\text {stt }}-5^{\text {th }}$ centuries $\mathrm{AD}$.

d) The radiocarbon date from samples number 1, 2 and 4 are in range from $1970 \pm 130 \mathrm{yrBP}$ to $2090 \pm 85 \mathrm{yrBP}$, which are consistent with the thermoluminescence dates of the pottery in monument.

Table 3. The radiocarbon dates in Go Thap monument.

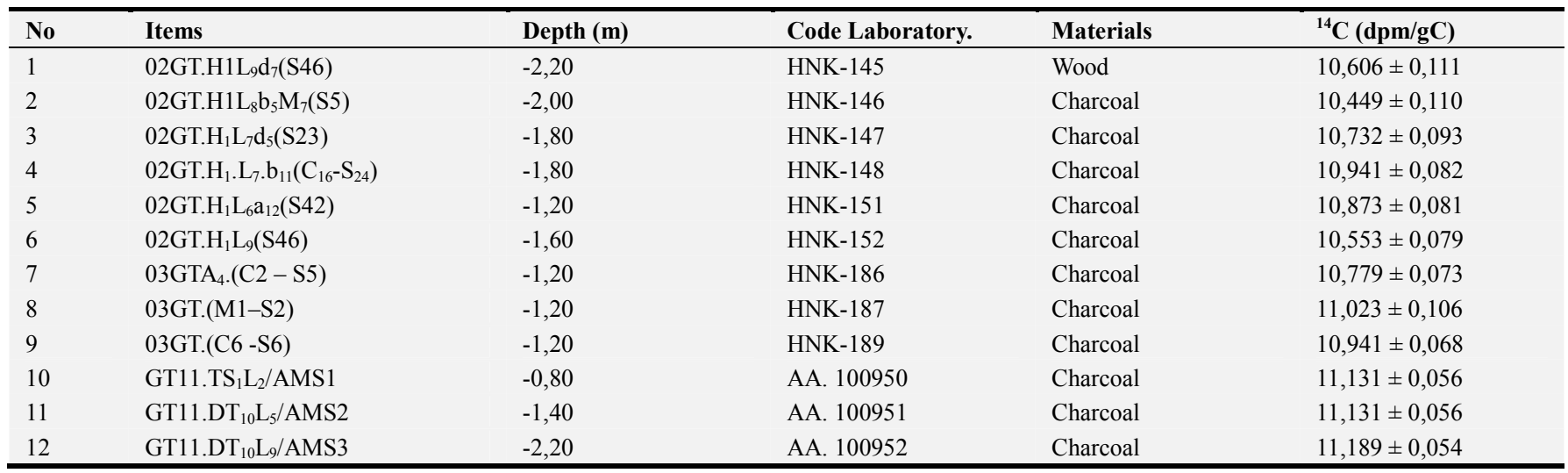

Table 3. Continued.

\begin{tabular}{|c|c|c|c|c|c|}
\hline \multirow{2}{*}{ No } & \multirow{2}{*}{ Items } & \multirow{2}{*}{$\delta^{13} \mathrm{C}$} & \multirow{2}{*}{ Age (yrBP) } & \multicolumn{2}{|c|}{ Calibration ${ }^{14} \mathrm{C}$ age range } \\
\hline & & & & 10 & 20 \\
\hline 1 & 02GT.H1L $\mathrm{L}_{9} \mathrm{~d}_{7}(\mathrm{~S} 46)$ & $-25,0 \% \mathrm{o}$ & $1970 \pm 130$ & 170BC-210AD & 400BC-350AD \\
\hline 2 & 02GT.H1L $\mathrm{L}_{8} \mathrm{M}_{7}$ (S5) & $-25,0 \% \mathrm{o}$ & $2090 \pm 85$ & $350 \mathrm{BC}-10 \mathrm{AD}$ & 370BC-70AD \\
\hline 3 & 02GT.H $\mathrm{L}_{7} \mathrm{~d}_{5}(\mathrm{~S} 23)$ & $-25,0 \% \mathrm{o}$ & $1875 \pm 70$ & 60AD-230AD & 40BC-330AD \\
\hline 4 & 02GT.H.H. $\mathrm{L}_{7} \cdot \mathrm{b}_{11}\left(\mathrm{C}_{16} \mathrm{~S}_{24}\right)$ & $-25,0 \% \mathrm{o}$ & $1720 \pm 60$ & 250AD-400AD & 130AD-440AD \\
\hline 5 & 02GT. $\mathrm{H}_{1} \mathrm{~L}_{6} \mathrm{a}_{12}(\mathrm{~S} 42)$ & $-25,0 \% \mathrm{o}$ & $1770 \pm 60$ & 130AD-350AD & $120 \mathrm{AD}-410 \mathrm{AD}$ \\
\hline 6 & 02GT.H $\mathrm{L}_{9}(\mathrm{~S} 46)$ & $-25,0 \% \mathrm{o}$ & $2010 \pm 60$ & 90BC-70AD & 180BC-130AD \\
\hline 7 & 03GTA4. $(\mathrm{C} 2-\mathrm{S} 5)$ & $-25,0 \% \mathrm{o}$ & $1840 \pm 55$ & 80AD-240AD & 50AD-340AD \\
\hline 8 & 03GT.(M1-S2) & $-25,0 \% \mathrm{o}$ & $1660 \pm 85$ & 250AD-540AD & 140AD-590AD \\
\hline 9 & 03GT.(C6 -S6) & $-25,0 \% \mathrm{o}$ & $1720 \pm 50$ & 25AD-390AD & $160 \mathrm{AD}-430 \mathrm{AD}$ \\
\hline 10 & GT11.TS $\mathrm{L}_{2} / \mathrm{AMS} 1$ & $-27,7 \%$ o & $1625 \pm 40$ & 380AD-540AD & $330 \mathrm{AD}-540 \mathrm{AD}$ \\
\hline 11 & 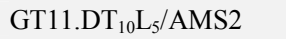 & $-28,6 \%$ o & $1765 \pm 40$ & 220AD-340AD & 130AD-390AD \\
\hline 12 & $\mathrm{GT}_{11 . \mathrm{DT}_{10} \mathrm{~L}_{9} / \mathrm{AMS} 3}$ & $-25,9 \%$ o & $1555 \pm 38$ & 430AD-550AD & 420AD-600AD \\
\hline
\end{tabular}

Note: - HNK indicates ${ }^{14}$ dates from Laboratory of Archaelology in HaNoi, Vietnam - AA indicates ${ }^{14} \mathrm{C}$ dates from Laboratory in University of Arizona, USA The ages are uncalibration. 


\section{Discussion and Implications}

From the Table 2 and 3, we can see that ages of the wood, charcoal and ceramic objects collected in the brick structures in Go Thap are ranging from $2100 \pm 105 \mathrm{yrBP}$ to $1555 \pm 38$ yrBP. Besides, the brick structures yielded over 300 gold leaves, of which, a great number are decorated. The images of gods include Vishnu, his mount Garuda, and some female deity or deities, perhaps Lakshmi, many gold leaves bear images of lotuses, conches and wheels, which can be interpreted, depending on the context, as either the attributes of Vishnu or as auspicious symbols $[2,7]$.

On the basis of these arguments, the thermoluminescence and radiocarbon dating we have identified that the brick structures excavated in Go Thap are not tombs, but foundations of Hindu shrines. Given the ${ }^{14} \mathrm{C}$ and TL ages of the brick structures, we recognize these bricks were initial construction episode from an early 1 st millennium $\mathrm{AD}$ date, and believe to have experienced multiple subsequent building or remodeling.

In comparison with Angkor Borei in Cambodia, we can see it coincides with the dates of the monuments in Go Thap. Results of the dating programs will help refine the regional chronology of the upper Mekong delta, perhaps even beyond Vietnam. This will also help with finding the origins and the beginning of brick architectural traditions in Southeast Asia $[12,18]$.

The research indicates that some religious brick monuments date as early as the 5 th century $\mathrm{AD}[5,11]$. Our dating program indicates that a similar pattern may be obtained in the delta around Oc Eo region. We await the results of future work on the brick structure monuments in the Lower Mekong Delta.

This paper has presented preliminary results of the ${ }^{14} \mathrm{C}$ and TL dating program. Our work thus far has contributed to clarify the historic culture of the Lower Mekong Delta, to understand the development of Oc Eo culture and its surrounding area. We hope it has also illustrated that the use of archaeometric analytical methods in conjunction with archaeological work is capable of revealing new facets of the social developments of these early complex systems.

\section{Conclusions}

Base on the the thermoluminescene and radiocarbon ages given in Table 2 and Table 3, we may considerated the brick structures finding at Go Thap site in the Lower Mekong delta basin have been dated in range from 1 st century $\mathrm{BC}$ to 6 th century $\mathrm{AD}$. These brick structures may be belonged to begining and developing period of Oc Eo culture in the mainland Southeast Asian region. This result also agree with the investigation on the brick structures found at the relics of Thoai-son district, An Giang province (Vietnam), far from Go Thap site around $80 \mathrm{~km}$ on the South-west.

Thermoluminesene age of ceramic collection was associated with the excavation layer, and correspond to the thermoluminescene dating of ceramic groups from Angkor Borei site in Cambodia, far from Go-Thap site round $80 \mathrm{~km}$ on the North - west, they are in ranging from 2nd century BC to 1 st century AD. Radiocarbon ages of charcoal ash objects discovered at the bottom cultural layer in the brick structures are consistent with the time of initial occupation of Go-Thap site, and consident at the first century BC.

\section{Acknowledgements}

The work was supported by grants from the National Project for Space, (grant no VT-UD. 10/17-20). We also thank VAST for their funds, hospitality and encouragement during this work.

\section{References}

[1] Aitken M. J. 1985. Thermoluminícence dating. Academic press. New York.

[2] Anna Aleksandra Slaczka, 2011. The brick structures of Go Thap - Tombs or Temples. Bulentin of the Indo-Pacific Prehistory Association 31: 109-117.

[3] Bishop P, Savid C. W. Sanderson, Miriam T. Stark. 2004. OSL and radiocarbon dating of a pre-Angkorian canal in the Mekong delta, southern Cambodia. Journal of Archaeology Science 31: 319-336.

[4] Bui Thi Hong, Vu Anh Hung, Nguyen Quang Mien, Bui Van Loat. 2018. Study of heating rate effect on thermoluminescence glow curves of $\mathrm{LiF}: \mathrm{Mg}, \mathrm{Cu}, \mathrm{P}$. VNU Journal of Science Mathematics - Physics, Vol. 34, No. 1 (2018): 46-51.

[5] Coedès, G. 1931. Deux inscriptions sanskrites du Fou-nan. Bulletin de l'École française d'Extrême Orient 31: 1-8.

[6] Dao Linh Con. 1998. The Oc Eo burial group recently excavated at Go Thap (Dong Thap Province, Viet Nam). In P. Y. Manguin (ed), Southeast Asian Archaeology 1994: Proceeding of the 5th International Conference of the European Association of Southeast Asian Archaeologists, Volume 1: 111-117, Hull: Centre for Southeast Asian Studies, University of Hull.

[7] Dang Van Thang, Vo Thi Huynh Nhu. 2012. The Religious Centre of Go Thap (Dong Thap), Archaeology, No 2 (2012): 71-90.

[8] Le Xuan Diem, Dao Linh Con, Vo Si Khai. 1995. Oc Eo Culture - Recent discoveries. Social Sciences Publishing House, Hanoi (in Vietnamese).

[9] Le Thi Lien. 2005. Di tich Go Thap va nhung van de cua van hoa Oc Eo [Go Thap site and the problems of Oc Eo culture], Proceeding of the International Conference: One century of Vietnamese Archaeology", Vol. II: 845-869. Hanoi: Social Sciences Publishing House, Hanoi. (in Vietnamese).

[10] Le Thi Lien, 2006. Excavations at Minh Su Mound, Go Thap site, Dong Thap Province, South Vietnam. In E. Bacus, I. C. Glover, V. C. Piggot (eds.), Uncovering Southeast Asia's past: Selected papers from the 10th International Conference of the European Association of Southeast Asian Archaeologists: 232-244. Singapore: NUS Press. 
[11] Malleret. L, 1959, 1960, 1963. L'Archaeologie du Delta du Mékong, Part 1. L'exploration arche 'ologique et les fouilles d'Oc-Eo. École Française d'Extrême-Orient, Paris.

[12] Miriam T. Stark. 2006. Re-Ankorian settlement trends in Cambodia's Mekong delta and the Lower mekong Archeological Project. Indo-Pacific prehistory association bullentin, Vol. 26 (2006): 98- 109.

[13] Nguyen Quang Mien, Bui Van Loat 2005. Thermoluminescence properties of the different size quartz grains. Proceeding of the 3rd National Conference on Modern problems in Optics and Spectroscopy: 190-195. Vietnam National University Publishers.

[14] Nguyen Quang Mien, Bui Van Loat 2007. Some thermoluminescence dates of ancient ceramics in Go Thap (DongThap). Proceeding of the International Workshop on Advances in Optics, Photonics, Spectroscopy and Application: 412-417. Vietnam Academic Press. Sciences and Technology Publishers.
[15] Nguyen Quang Mien, Bui Van Loat, Thai Khac Dinh 2009. Dating ceramic samples by thermoluminescence approach in the lab. of the Vietnam institute of Archaeology. Journal of Archaeology: 80-92. Social Sciences Publishing House, Hanoi. (in Vietnamese).

[16] Nguyen Quang Mien, Trinh Nang Chung 2010. Thermoluminescence characteristic of $\mathrm{LiF}(\mathrm{Mg}, \mathrm{Cu}, \mathrm{P})$ after exposing the alpha radiation. Proceeding of the First Academic Conference on Natural Science for master and $\mathrm{Ph}$. D students from Cambodia, Laos, Vietnam. pp. 58-65. Vietnam National University in HCM city Publishing House.

[17] Nguyen Thi Huynh Phuong: Oc Eo Culture: A case study of Oc Eo artifacts in Southern Vietnam. Can Tho University Journal of Science Vol 3 (2016): 133-142.

[18] Sanderson D. C. W, P. Bishop, M. T. Starkc, J. Q. Spencer 2003. Luminescence dating of canal sediments from Angkor Borei, Mekong Delta, Southern Cambodia: Quaternary Science Review 22: 1111-1121. Aitken M. J. 1985. Thermoluminícence dating. Academic press. New York. 